\title{
Lung mucociliary clearance in rheumatoid disease
}

\author{
P. P. SUTTON, N. KADIR,* D. PAVIA, N. F. SHEAHAN, AND \\ S. W. CLARKE \\ From the Departments of Thoracic Medicine and ${ }^{*}$ Rheumatology, Royal Free Hospital, London
}

SUMMARY Lung mucociliary clearance rates were measured in 11 patients with rheumatoid disease and found to be unaltered when compared with those of a group of matched control subjects. The results are discussed in relation to the increased incidence of respiratory infection in patients with rheumatoid disease and also to the recently reported finding of increased airways obstruction in these patients.

Rheumatoid disease is a multisystem disorder and has definite and frequent connections with various types of lung disease. Pleuritic involvement is a common feature and may occur early in the disease process. Nodule formation (with or without cavitation), rheumatoid pneumoconiosis, fibrosing alveolitis, and vascular changes are also recognised. ${ }^{1}$ Upper lobe fibrosis, ${ }^{2}$ more commonly seen in ankylosing spondylitis, and gold and penicillamine induced lung disease have also been reported. ${ }^{3-5}$

Although less striking, infection is probably the commonest respiratory problem in rheumatoid disease; an increased incidence of pneumonia and bronchiectasis has been found. ${ }^{6-8}$ Empyema, although uncommon, also has an increased incidence, ${ }^{9}$ and pulmonary tuberculosis appears with increased frequency. ${ }^{1}$ The increased incidence of chronic bronchitis found in some studies may be due to higher cigarette consumption in the patients than in the appropriate control group. ${ }^{10}$ No significant increase in emphysema was found in a radiological study by Stack and Grant. ${ }^{11}$ Sepsis was the direct cause of death in $20-25 \%$ of patients with rheumatoid disease, of which pneumonia and septicaemia were the most frequent fatal infections. ${ }^{12} 13$

The lung has 3 defence mechanisms for clearing itself of inhaled particulate matter (including bacteria): lung mucociliary clearance, cough, and alveolar clearance. Alveolar clearance is the slow phase of clearance and concerns the removal of insoluble particles deposited in the alveolar regions and occurs mainly via the alveolar macrophage. Mucociliary clearance of the ciliated or conducting

Accepted for publication 22 January 1981

Correspondence to Dr P. P. Sutton, Department of Thoracic Medicine, Royal Free Hospital, Pond Street, London NW3 2QG. airways is (in health) probably more important than cough in maintaining bronchial clearance of secretions and debris.

In view of the increased incidence of respiratory infection and the frequency of other forms of respiratory involvement, it was decided to investigate tracheobronchial mucociliary clearance in a selected group of patients with rheumatoid disease.

\section{Patients and methods}

\section{Patients}

Eleven patients (10 female) with active seropositive rheumatoid disease were studied. They were undergoing inpatient treatment primarily for their rheumatoid disease, and all had considerable early morning stiffness. The mean duration of their symptoms was 14 years (range 2 to 30 years); mean haemoglobin $11.5 \mathrm{~g} / \mathrm{dl}$, mean erythrocyte sedimentation rate $54 \mathrm{~mm} / \mathrm{h}$. Six patients were receiving penicillamine and 3 were receiving gold therapy. In addition 7 patients were taking prednisolone $5 \mathrm{mg}$ / day. All were taking various nonsteroidal antiinflammatory drugs, but none were taking aspirin.

Patients with a history suggestive of chronic bronchitis, asthma, bronchiectasis, or other significant respiratory disease were excluded. All patients had a normal chest radiograph. Lung function tests were not included at this point of patient selection. There was no other relevant illness in these patients except that 2 had symptomatic ischaemic heart disease and 1 had clinical evidence of Sjögren's syndrome. Care was taken during selection to exclude any patients with acute respiratory infection within the last 1 month, as some infections, notably influenza $\mathbf{A}$ and mycoplasma pneumonia, depress mucociliary clearance. ${ }^{14}{ }^{15}$ Patients were also 
Table 1 Mean (土'SD) physical characteristics and tobacco consumption for 11 patients with rheumatoid disease and 11 control subjects

\begin{tabular}{llll}
\hline Characteristic & $\begin{array}{l}\text { Rheumatoid } \\
\text { disease } \\
(\text { mean } \pm S D)\end{array}$ & $\begin{array}{l}\text { Control } \\
(\text { mean } \pm S D)\end{array}$ & $P$ \\
\hline $\mathbf{n}$ & 11 & 11 & - \\
M/F & $1 / 10$ & $5 / 6$ & - \\
Age (yr) & $62 \pm 11$ & $60 \pm 13$ & $\mathrm{NS}$ \\
Height (m) & $1.63 \pm 0.05$ & $1.64 \pm 0.07$ & $\mathrm{NS}$ \\
$\begin{array}{l}\text { Tobacco consumption } \\
\text { (pack years) }\end{array}$ & $12 \pm 18$ & $17 \pm 21.4$ & $\mathrm{NS}$ \\
\hline
\end{tabular}

NS = not significant

excluded if they were taking beta- 2 agonists and theophylline, both of which are currently thought to alter (enhance) mucociliary clearance rates. ${ }^{16}$

The control group contained a similar number (6 females, 5 males) who were either healthy volunteers (9 subjects) or outpatients attending with mild degenerative joint disease ( 2 subjects). The physical characteristics and mean tobacco consumption of both groups are given in Table 1. There was no significant difference in these features berween the 2 groups. The difference in sex ratio was not thought to be important, as no difference in mucociliary clearance rates between male and female has been found. ${ }^{17}$

\section{LUNG MUCOCILIARY CLEARANCE}

Mucociliary clearance was measured by the objective and essentially noninvasive technique (in current use) of Thomson and Short. ${ }^{18}$ Polystyrene particles of a uniform diameter $(5 \mu \mathrm{m})$ firmly labelled with ${ }^{99} \mathrm{~m}$ technetium were generated by the spinning disc technique ${ }^{19}$ and inhaled from an airtight tank in 8 separate respiratory manoeuvres of a predetermined volume $(450 \mathrm{ml})$ starting from normal end expiration, using a Krogh spirometer. After inhalation the subject rinsed his mouth with water and swallowed to eliminate any contribution from the mouth, oropharynx, and oesophagus during subsequent counting. The total radiation burden did not exceed $30 \mu \mathrm{Ci}$ of ${ }^{99} \mathrm{~m}_{\text {technetium, }}$ resulting in a lung-absorbed dose of $13 \mathrm{mrem}$. The flow rate during inhalation (which is important in determining the initial distribution of the inhaled particles within the lungs) was measured with a pneumotachygraph.

The distribution of the polystyrene particles was recorded by a rectilinear gamma scanner which travelled in vertical columns at $2 \cdot 5 \mathrm{~cm}$ intervals from the chest midline to the periphery of the seated subject. A 'penetration index' was obtained by relating the count obtained from a central area (near the midline) to a peripheral area as a quantitative measure of the initial topographical distribution of the deposited radio-aerosol.

The subject was then seated between 2 opposing scintillation detectors, one situated anteriorly and the other posteriorly to the chest. Both detectors were suitably collimated to exclude any irradiation originating from swallowed material in the oesophagus or stomach. Counting was taken over 100 seconds at 30-minute intervals for a total of 6 hours and corrected for radioactive decay and background activity. A further count was taken at 24 hours and was considered to be equated with alveolar deposition, that is, deposition beyond the ciliated/ conducting airways.

The subjects were under continual supervision; times of cough and volume and radioactivity of sputum produced were noted; smokers were asked to refrain from cigarette consumption from midnight of the previous day and for the duration of the study. Normal ambulation and activity were continued wherever possible, as was routine medication.

Before the study began all patients underwent routine pulmonary function testing. The following were measured: forced expiratory volume in 1 second $\left(\mathrm{FEV}_{1}\right)$ and forced vital capacity (FVC) by means of a dry bellows spirometer (Vitalograph); peak expiratory flow rate (PEFR) with a Wright peak flow meter; flow rates obtained from the maximal flow volumes at $25 \%\left(\dot{\mathrm{V}}_{25} \max \right)$ and $50 \%$ $\left(\dot{\mathrm{V}}_{50} \max \right)$ of the vital capacity with an Ohio spirometer with a Bryans X-Y recorder. The best value out of 3 technically acceptable recordings was taken for each pulmonary function index. Lung transfer of carbon monoxide was not included, as the investigation was primarily concerned with the function of the ciliated or conducting airways rather than the respiratory regions involved in gas exchange.

Statistics. Since the data were not normally distributed, nonparametric statistical methods were used to analyse them. Statistical analysis was made by the Wilcoxon test for unpaired samples.

\section{Results}

Results of the pulmonary function tests are shown in Table 2. There was no significant difference between the 2 groups for any of the ventilation indices measured. The depressed values obtained for flow rates at $25 \%$ and $50 \%$ of vital capacity probably reflect the inclusion of patients who were smokers, as these measurements are an indication of small airways obstruction. Nine of the 11 patients with rheumatoid disease were current or exsmokers, 
Table 2 Results of pulmonary function testing expressed as percentage of normal values ${ }^{27}$ in the patients with rheumatoid arthritis and control group

\begin{tabular}{lllll}
\hline & $\begin{array}{l}\text { Pulmonary } \\
\text { function } \\
\text { test }\end{array}$ & $\begin{array}{l}\text { Rheumatoid } \\
\text { disease } \\
(\text { mean } \pm S D)\end{array}$ & $\begin{array}{l}\text { Control } \\
(\text { mean } \pm S D)\end{array}$ & $P$ \\
\hline $\begin{array}{l}\text { Large airway } \\
\text { function }\end{array}$ & FEV $_{1}$ & $99 \pm 25$ & $110 \pm 21$ & NS \\
& FVC & $98 \pm 19$ & $103 \pm 21$ & NS \\
& FEV $_{1} / \mathrm{FVC}$ & $80 \pm 11$ & $86 \pm 7$ & NS \\
& PEFR & $96 \pm 18$ & $102 \pm 27$ & NS \\
$\begin{array}{l}\text { Small airway } \\
\text { function }\end{array}$ & MMFR & $99 \pm 46$ & $130 \pm 37$ & NS \\
& $\dot{V}_{25}$ max & $45 \pm 26$ & $41 \pm 18$ & NS \\
& $\dot{V}_{50 m a x}$ & $67 \pm 29$ & $64 \pm 21$ & NS \\
\hline
\end{tabular}

NS = not significant.

though none had evidence of chronic bronchitis as defined by the Medical Research Council criteria. There was no statistically significant difference in the mean tobacco consumption expressed in packyears between the patients and the control subjects (Table 1). On direct questioning 4 of the 11 patients with rheumatoid disease felt they had exertional dyspnoea, but 3 of these had difficulty in distinguishing this from limitation caused by their disease activity. Two of these patients also had additional ischaemic heart disease. There was no evidence of increased respiratory infections in this group and no evidence of other respiratory illness.

Although the average inhalation flow rate for the particles was slightly higher in the patients with rheumatoid disease than in the control group (36.0 $\pm 8.61 / \mathrm{min}$ for the group with rheumatoid disease and $26 \cdot 3 \pm 5 \cdot 4 \mathrm{l} / \mathrm{min}$ for the control group), this did not result in a significant difference in the penetration index for the 2 groups $(0.59 \pm 0.16$ and $0.57 \pm 0.26$, respectively). Unless the distribution of particles within the tracheobronchial tree is comparable in any 2 groups studied, an apparently enhanced whole-lung clearance rate may be explained on the basis of the more rapid clearance of centrally placed particles (which do not have so far to 'travel' as peripheral particles before being 'cleared' by expectoration or swallowing).

The tracheobronchial mucociliary clearance curve (corrected for radioactive decay) for both groups is shown in Fig. 1. There was no statistically significant difference between the 2 curves when analysed at 2 , 4 , and 6 hours. As cough during the clearance phase will also contribute to the values obtained, it should be noted that there was no significant difference in the amount of coughing or sputum produced between the 2 groups.

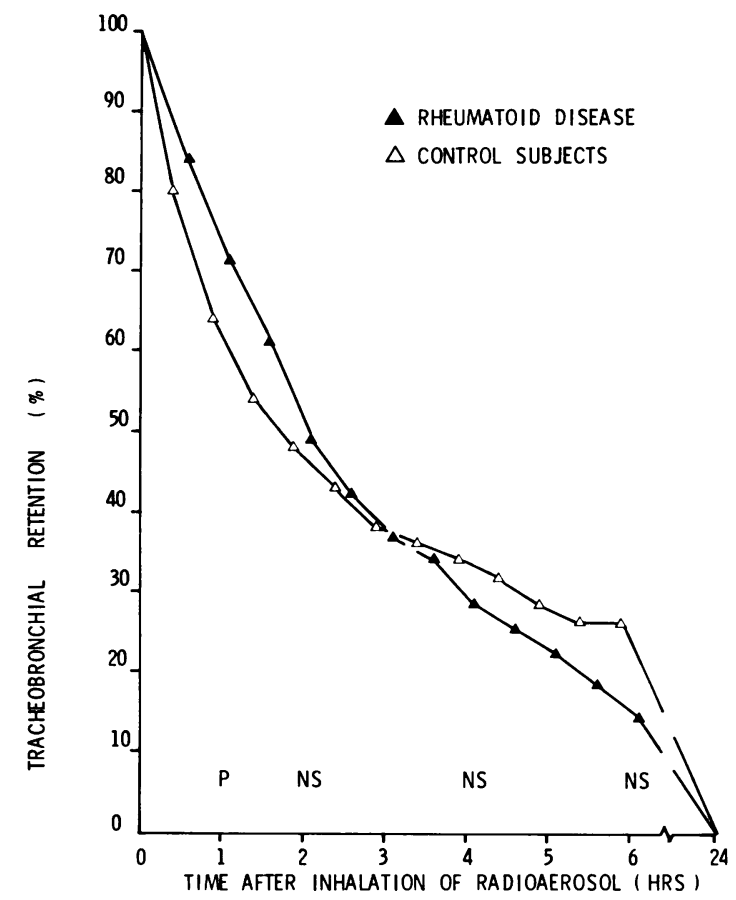

Fig. 1 Mean tracheobronchial clearance curves for 11 patients with rheumatoid disease and 11 matched control subjects.

\section{Discussion}

It is possible that the increased incidence of infection in patients with rheumatoid disease refers to those patients treated with corticosteroids. Ward and Atcheson ${ }^{12}$ showed an increased incidence of urinary tract infections in patients taking more than $7.5 \mathrm{mg}$ prednisone daily, and Talbott and Calkins ${ }^{6}$ in a post-mortem study of 37 patients with rheumatoid disease showed a higher incidence of terminal bronchopneumonia in the corticosteroid treated group. However, these represent a selected group with an increased severity of symptoms, and the general view is that corticosteroids are probably not responsible for the higher incidence of infection. ${ }^{20}$ Other possible explanations are related to the general debility of the patient, decreased function of granulocytes secondary to their ingestion of immune complexes, or impaired host response following treatment. ${ }^{13}$ In many cases the infection precedes the symptoms of rheumatoid disease, and infection has been advanced as being involved in the aetiology. ${ }^{21}{ }^{22}$ We found no evidence of increased infection in this study, but the numbers involved 
were probably too small and the experimental design was not directed primarily to detecting this.

The results from the mucociliary clearance show that there is no impairment of ciliary clearance of inhaled particles in patients with rheumatoid disease when compared with a matched control population. Mucociliary clearance rates are known to be depressed in some disease states associated with respiratory infection, ${ }^{16}$ but we have clearly shown that the explanation for increased respiratory infection in rheumatoid disease must lie in some other altered host defence mechanism and not in depressed mucociliary clearance. The method used in this study has been shown to be effective in demonstrating differing rates of mucociliary clearance in several situations. ${ }^{16}$ For example, Bateman et $a .^{23}$ have shown that clearance is significantly slower in 6 asthmatic subjects as opposed to a similar number of (matched) control subjects.

Although matched for age, tobacco consumption, and penetration of inhaled particles, the 2 populations differed in regard to medication. The control group were taking no medication during the study, but the patients with rheumatoid disease were taking a variety of anti-inflammatory agents in addition to penicillamine, sodium aurothiomalate, and corticosteroids. Corticosteroids have been shown to enhance the rate of clearance in stable asthmatic subjects, but their action in healthy subjects has not been studied. Similarly, the role of anti-inflammatory agents on mucociliary clearance has not been investigated, but from these results it would seem unlikely that they significantly alter mucociliary clearance.

In addition to the mostly restrictive processes previously mentioned, airway obstruction has been reported with increasing frequency in patients with rheumatoid disease. Collins et al. $^{24}$ found reduced mean maximal expiratory flow rates (indicative of small airways obstruction) in 23 out of 43 patients studied. This was not influenced by the amount of cigarette smoking, aspirin ingestion, or extent of disease activity. Geddes et al. ${ }^{25}$ found evidence of airway obstruction in at least one-third of their patients. One explanation suggested was that airway obstruction might be caused by frequent respiratory tract infections. Cases of acute bronchiolitis, unusual in adult patients, have also been reported in patients with rheumatoid disease followed by progressive airway obliteration. ${ }^{26} \mathrm{~A}$ postulated reason for this is that agents known to cause acute bronchiolitis, such as viruses and fumes, are handled in a defective way by patients with rheumatoid disease, who are thus unduly prone to develop an obliterative disease of the airways.

We found no evidence of large airway obstruction in our patients (Table 2), and the degree of small airways obstruction was compatible with that caused by smoking (and matched that of the control group). It might be that a subgroup of patients exists, namely, those who develop obstructive bronchiolitis, and that clearance should be investigated in these patients. As to respiratory infection in general, no abnormality in mucociliary clearance was found that might contribute to the explanation.

The only other study that has investigated mucociliary clearance in these patients is one by Fairfax et al. (personal communication), who investigated 8 patients with Sjögren's syndrome. Mucociliary clearance was found to be normal, although only 3 of these patients had 'probable' rheumatoid disease and none had 'definite' rheumatoid disease (American Rheumatism Association criteria).

We thank Dr A. T. Richardson and Dr E. D. R. Campbell for allowing us to study patients under their care.

\section{References}

1 MacFarlane J D, Dieppe P A, Rigden B G, Clark J J H. Pulmonary and pleural lesions in rheumatoid disease. Br J Dis Chest 1978; 72: 288-300.

2 Petrie G R, Bloomfield P, Grant I W B, Crompton G K. Upper lobe fibrosis and cavitation in rheumatoid disease. Br J Dis Chest 1980; 74: 263-7.

3 Daymond J J, Griffiths I D. Pulmonary disease due to gold in rheumatoid arthritis. Rheumatol Rehabil 1980; 19: $120-1$.

4 Petersen J, Møller I. Miliary pulmonary infiltrates and penicillamine. Br J Radiol 1978; 51 : 915-6.

5 Sternlieb I, Bennett B, Scheinberg I H. D-penicillamine induced Goodpasture's syndrome in Wilson's disease. Ann Intern Med 1975; 82: 673-6.

6 Talbott J A, Calkins E. Pulmonary involvement in rheumatoid arthritis. JAMA 1964; 189: 911-3.

7 Kay A. Infection in rheumatoid arthritis. Lancet 1967; ii: 152.

8 Walker W C. Pulmonary infections and rheumatoid arthritis. $Q J$ Med 1967; 36: 239-51.

9 Jones F L, Glodgell R C. Empyema in rheumatoid pleuropulmonary disease. Ann Intern Med 1971; 74: 665-71.

10 Editorial. Pulmonary dysfunction in rheumatoid disease. J Asthma Res 1972; 10: 79-80.

11 Stack B H R, Grant I W B. Rheumatoid interstitial lung disease. Br J Dis Chest 1965; 59: 202.

12 Ward J R, Atcheson S G. Infection in rheumatoid arthritis. Compr Ther 1977; 2 : 46-52.

13 Hollingsworth J W, Saykaly R J. Systemic complications of rheumatoid arthritis. Med Clin North Am 1977; 61 : 217-218.

14 Camner P, Jarstrand C, Philipson K. Tracheobronchial clearance in patients with influenza. Am Rev Respir Dis 1973; 108: 131-5.

15 Jarstrand C, Camner P, Philipson K. Mycoplasma pneumoniae and tracheobronchial clearance. Am Rev Respir Dis 1974; 110: 415-9. 
16 Pavia D, Bateman J R M, Clarke S W. Deposition and clearance of inhaled particles. Bull Eur Physiopath Respir 1980; 16: 335-66.

17 Pavia D, Short M D, Thomson M L (1970). No demonstrable long term effects of cigarette smoking on the mucociliary mechanism of the human lung. Nature 1970; 226: 1228-31.

18 Thomson M L, Short M D. Mucociliary function in health, chronic obstructive disease and asbestosis. J Appl Physiol 1969; 26: 535-9.

19 May K R. An improved spinning top homogenous spray apparatus. J Appl Physiol 1949; 20 : 932-8.

${ }^{20}$ Editorial. Infection in rheumatoid disease. $\mathrm{Br} \mathrm{Med} \mathrm{J} \mathrm{1972;}$ ii: $549-50$.

21 Baum J. Infection in rheumatoid arthritis. Arthritis Rheum 1971; 14: 135-7.
22 Mathieu J P, Stack B H R, Dick W C, Buchanan W W. Pulmonary infection and rheumatoid arthritis. $\mathrm{Br} J \mathrm{Dis}$ Chest 1978; 72: 57-61.

23 Bateman J R M, Pavia D, Sheahan N F, Clarke S W. Tracheobronchial clearance in asthma. Thorax 1979; 34: 418.

24 Collins R L, Turner A A, Johnson A M, Whitley N O, McClean $R \quad L$. Obstructive pulmonary disease in rheumatoid arthritis. Arthritis Rheum 1976; 19: 623-8.

25 Geddes D M, Webley M, Emerson P A. Airway obstruction in rheumatoid arthritis. Ann Rheum Dis 1979; 38: $222-5$.

26 Geddes D M, Corrin B, Brewerton D A, Davies R J, Turner-Warwick M. Progressive airway obliteration in adults and its association with rheumatoid disease. $Q J$ Med 1977; 184: 427-44. 